\title{
IMPUESTO A LOS INGRESOS BRUTOS: “AVE FÉNIX" DE LA ESTRUCTURA TRIBUTARIA SUBNACIONAL ${ }^{1}$
}

\author{
Alberto Porto* \\ Marcelo Garriga** \\ Walter Rosales***
}

enviado: diciembre 2013 - aceptado: abril 2014

\section{Resumen}

La estructura de un sistema tributario comprende dos aspectos: la composición de los recursos públicos y la estructura de los impuestos en particular. En este trabajo se estudian las dos cuestiones para los recursos propios de la Provincia de Buenos Aires. La composición ha experimentado un cambio notable a lo largo del tiempo. Ingresos Brutos ha sustituido a los otros tributos provinciales, especialmente a los que gravan la propiedad inmueble. El impuesto ha tenido cambios importantes a lo largo del tiempo y exhibe actualmente una compleja estructura de alícuotas que se estudia teórica y empíricamente.

Clasificación JEL: H22, H71

Palabras Clave: estructura tributaria, impuestos provinciales, ingresos brutos.

\footnotetext{
* porto.alb@gmail.com. FCE-UNLP

** marcelogarriga@yahoo.com.ar;

*** walter.rosales@depeco.econo.unlp.edu.ar.

1 Versiones preliminares se presentaron en las $45^{\circ}$ Jornadas Internacionales de Finanzas Públicas, Universidad Nacional de Córdoba, 2012 y en la XLVIII Reunión Anual de la AAEP (Rosario, 2013). Se agradecen los comentarios del Prof. Ernesto Rezk y del Dr. Darío Rossignolo.
} 


\begin{abstract}
The tax structure includes two aspects: the composition of the public resources and the structure of the taxes in particular. In this paper both questions are studied for the own revenues of the Buenos Aires province. The composition has experienced a notable change throughout the time. Gross receipts taxes replaced the other provincial taxes, especially the property tax. The tax has had important changes along the time and exhibits nowadays a complex structure of tax-rates that is studied theoretical and empirically.
\end{abstract}

JEL Clasification JEL: H22, H71

Key Words: tax structure, subnational taxes, gross receipts taxes.

\title{
INTRODUCCION
}

La estructura de un sistema tributario es el resultado de un balance de objetivos conflictivos, dadas las restricciones que enfrenta la economía. La estructura comprende dos aspectos. Por un lado, la composición de los recursos públicos (número e importancia relativa de los impuestos) y, por otro lado, la estructura de los impuestos en particular (principalmente bases imponibles, alícuotas, exenciones y deducciones). Las dos cuestiones han sido objeto de estudios teóricos y empíricos y en las explicaciones compiten las teorías normativa y positiva de la imposición. En este trabajo se estudian aspectos de las dos cuestiones (composición de la recaudación y estructura de un impuesto) para el caso del impuesto a los ingresos brutos (IIB) en la Provincia de Buenos Aires.

El trabajo está organizado en la forma siguiente. En la sección I, luego de un breve repaso por la literatura, se presenta la evolución a lo largo del tiempo de la composición de los recursos propios, que pasó de estar dominada por los impuestos sobre la propiedad inmueble a estar dominada por los impuestos sobre los ingresos brutos ("turnover tax" o "gross receipts taxes"). A partir de un modelo teórico simple de determinantes políticos de la composición se sugiere que el resultado puede ser explicado en base a la "visibilidad" de los tributos, la posibilidad de exportarlo a otras jurisdicciones, lo incierto de su incidencia, la coincidencia o no entre el ciclo de los ingresos de las personas y el ciclo de los pagos del impuesto, y la elasticidad ingreso de la recaudación. La sección II presenta la evolución de la estructura del impuesto entre 1978 y 2010 y reformula el modelo de la sección I para estudiar teórica y empíricamente los determinantes de las alícuotas por 
sectores. Los resultados sugieren que en la fijación de las alícuotas influyen el poder de lobby de cada actividad, el número de contribuyentes y las alícuotas de las jurisdicciones vecinas. También influyen las características propias de cada actividad. En la sección III se concluye.

\section{COMPOSICION DE LOS RECURSOS PROPIOS DE LA PROVINCIA DE BUENOS AIRES}

\section{I.1. Literatura: algunas hipótesis}

La composición de la recaudación es uno de los aspectos a considerar al estudiar la estructura tributaria de una jurisdicción. En la literatura se han formulado varias hipótesis para explicar sus determinantes. Una breve síntesis se presenta seguidamente.

Una hipótesis se vincula con el concepto de "ilusión fiscal" introducido en la literatura económica por Puviani (1897). La composición de los recursos surgirá de minimizar la percepción fiscal de los contribuyentes: por ejemplo, recursos que provienen de la propiedad pública, impuestos indirectos (incluidos en el precio de los bienes) vs. los directos; inflación, deuda pública, los que gravan eventos inusuales que resultan agradables para las personas (compra de automóviles, viviendas, herencias, juegos de azar); los que tiene un patrón de incidencia incierto; y los que se pagan en cuotas diarias vs. los que se pagan de una vez o pocas veces.

Musgrave (1969) sugiere que la composición depende de la etapa de desarrollo económico de un país. En las primeras etapas de desarrollo predominan los impuestos fáciles de recaudar $\mathrm{y}$, en etapas posteriores, los impuestos que son más complicados de recaudar, con costos de administración más altos. Esta hipótesis enfatiza los costos de recaudación como determinante de la composición de los recursos; es una hipótesis de minimización de los costos de recaudación.

Pommerehe y Schneider (1983) explican los cambios en la composición suponiendo que los políticos tienen preferencias definidas por distintos tipos de tributos, reflejando su ideología o sus objetivos distributivos. Esta línea de explicación se vincula con la larga discusión sobre imposición directa e indirecta. La literatura asigna a la imposición directa el objetivo de equidad -debido a que los 
impuestos "directos" pueden ajustarse a las características de los individuos- y la imposición indirecta al objetivo recaudatorio-suponiendo que se establecen sobre los bienes con independencia de las características de compradores y vendedores.

En la teoría de la imposición óptima sobre bienes la estructura de las alícuotas resulta de igualar, para todos los bienes, la carga excedente marginal por peso recaudado -contemplando distintos objetivos y restricciones (entre otros, Ramsey, 1927; Diamond y Mirrlees, 1971; Atkinson y Stiglitz, 1976).

Hettich y Winer (1984) formulan un modelo general para todos los agentes políticos, sin considerar su filiación política. A diferencia de Pommerehe y Schneider suponen que el objetivo de los gobiernos es minimizar el costo político de recaudar una cierta suma; el objetivo se logra cuando el costo político marginal se iguala para todos los bienes. En Hettich y Winer (1999) se extiende el modelo para contemplar restricciones políticas y económicas de obtener la recaudación, que resulta de igualar el costo político marginal de la recaudación con el beneficio político marginal del gasto público.

Ashworth y Heyndels (2001) estudian los cambios de la estructura tributaria a lo largo del tiempo. Suponen que el gobierno tiene una estructura tributaria ideal y que los shocks exógenos lo apartan de esa estructura. El proceso de vuelta a la estructura ideal depende de la fortaleza/debilidad del gobierno. Este proceso toma más tiempo si el gobierno es débil (está fragmentado). A mayor fragmentación del gobierno, menos cambiará la estructura tributaria. En el trabajo estudian el cambio en la estructura tributaria en los países de la OECD -cuanto la estructura tributaria de un país difiere de la estructura internacional, un "ideal" que es igual a la estructura tributaria del resto de los países de la OECD.

I.2. Composición de los recursos propios de la provincia de Buenos Aires. Inmobiliario vis a vis Ingresos Brutos

En esta sección se estudia la composición de los recursos propios de la provincia de Buenos Aires. La atención se centra en los dos principales impuestos, inmobiliario e ingresos brutos, que representan alrededor del $85 \%$ del total. Se comienza con un breve detalle de la evolución de las recaudaciones a lo largo del tiempo, continuando con la evolución del actual impuesto sobre los ingresos brutos y el desarrollo de un modelo que ayuda a explicar el cambio temporal en la composición. 
En la Figura 1 se presenta la información de la composición, entre inmobiliario e ingresos brutos, de los recursos tributarios propios de la Provincia de Buenos Aires desde 1885 hasta 2010. El cambio ha sido notable. El actual impuesto sobre los Ingresos Brutos ha tenido una participación fuertemente creciente a lo largo del tiempo representando en la actualidad tres cuartos de la recaudación total. Ha sustituido como fuente de financiamiento a los otros tributos provinciales, especialmente a los que gravan la propiedad inmueble que pasaron de alrededor del $50 \%$ de lo recaudado hasta mediados del siglo anterior a menos del $10 \%$ a partir de 2007. Un modelo simple para explicar este cambio se presenta en la sección II.

Figura 1. Participación (\%) de los impuestos sobre Ingresos Brutos e Inmobiliario en total de recursos tributarios. 1885-2010

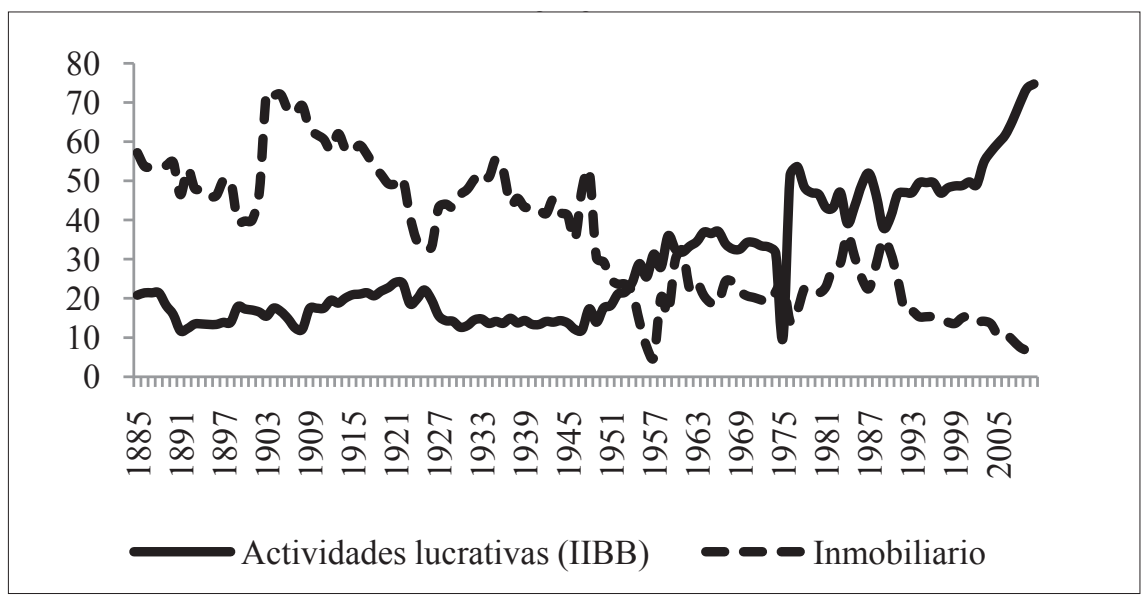

Fuente: Elaboración propia.

\section{I.3. Evolución de los tributos sobre los ingresos brutos desde 1885}

El antecedente del actual impuesto sobre los ingresos brutos se remonta a la época del Virreinato del Río de La Plata (1776) que estableció un régimen de intendencias. Esta nueva unidad política estaba constituida por dos regiones con recursos fiscales de distinto origen: la Caja de Potosí, en el norte, con fondos de la minería y la acuñación de monedas, y la de Buenos Aires, en el sur, que recibía la recaudación de gravámenes originados en el comercio (las "alcabalas", originarias 
de España ${ }^{2}$ ). A partir de 1821, las provincias mantuvieron el esquema de ingresos basado en las alcabalas, hasta el periodo de la organización nacional.

La evolución de los tributos sobre las actividades lucrativas en la Provincia de Buenos Aires (con distintas denominaciones), que culmina con el actual impuesto sobre los Ingresos Brutos, puede apreciarse, desde 1885 hasta la actualidad, en la Tabla 1.

Al comienzo el período existía un único impuesto (Patentes Fijas); en 1909 aparece el impuesto sobre Alcoholes, Naipes y Tabaco; se agrega luego Industria y Comercio (desde 1911), Licencia de Perfumes y Artículos de Tocador (1932), Licencia para la Fabricación de Bebidas Gaseosas (1934-1935), Policía y Fiscalización de Seguros (1937) y Productos Agrícolas (1937 a 1947). En 1948, con la aparición del impuesto a las Actividades Lucrativas, se unificaron en uno solo los distintos tributos vigentes en ese momento. En 1961 se agregó el Impuesto sobre las Actividades Lucrativas Agropecuarias cuyo antecedente había sido el Impuesto sobre los Productos Agrícolas, vigente entre 1937 y1947.

Tabla 1. Evolución del impuesto a los Ingresos Brutos en la provincia de Buenos Aires

\begin{tabular}{ll}
\hline Período & Concepto \\
\hline $1885-1908$ & Patentes Fijas \\
& Patentes Fijas \\
& Alcoholes, Naipes y Tabaco \\
& Patentes Fijas \\
& Comercio e Industria \\
& Alcoholes, Naipes y Tabacos \\
& Patentes Fijas \\
& Comercio e Industria \\
& Alcoholes, Naipes y Tabacos \\
& Licencia Perfumes y Artículos de Tocador \\
& \\
2 Cortés Conde y Harriague (AFIP, 2010).
\end{tabular}




\begin{tabular}{|c|c|}
\hline Período & Concepto \\
\hline \multirow{5}{*}{1934} & Patentes Fijas \\
\hline & Comercio e Industria \\
\hline & Alcoholes, Naipes y Tabacos \\
\hline & Licencia Perfumes y Artículos de Tocador \\
\hline & Licencia Fabricación Bebidas Gaseosas \\
\hline \multirow{4}{*}{1935} & Patentes Fijas \\
\hline & Comercio e Industria \\
\hline & Alcoholes, Naipes y Tabacos \\
\hline & Licencia Fabricación Bebidas Gaseosas \\
\hline \multirow{3}{*}{1936} & Patentes Fijas \\
\hline & Comercio e Industria \\
\hline & Alcoholes, Naipes y Tabacos \\
\hline \multirow{5}{*}{$1937-1947$} & Patentes Fijas \\
\hline & Comercio e Industria \\
\hline & Alcoholes, Naipes y Tabacos \\
\hline & Policía y Fiscalización de Seguros \\
\hline & Productos Agrícolas \\
\hline $1948-1960$ & Actividades Lucrativas \\
\hline \multirow{2}{*}{ 1961-1974 } & Actividades Lucrativas \\
\hline & Actividades Lucrativas Agropecuarias \\
\hline 1975 & Patentes \\
\hline $1976-1977$ & Actividades Lucrativas (incluye las actividades agropecuarias) \\
\hline 1978 en adelante & Ingresos Brutos \\
\hline
\end{tabular}

Fuente: elaboración propia en base a Nuñez Miñana y Porto (1981) y normativa impositiva provincial

I.4. "Ave Fenix" de la estructura tributaria provincial

El impuesto siempre estuvo y continúa estando sujeto a fuertes críticas por sus efectos sobre la eficiencia económica y la equidad distributiva. A lo 
largo del tiempo se ha intentado, una y otra vez, sustituirlo por otros tributos y/o transformarlo de modo de superar las objeciones. Pero, como el ave de la mitología griega, el IIB tuvo el poder de renacer de sus propias cenizas. En este renacer es probable que el acostumbramiento al impuesto haya jugado un papel importante, tal como lo sugería Alberdi (1954): "Después de los cambios en la religión y en el idioma del pueblo, ninguno más delicado que el cambio en el sistema de contribuciones. Cambiar una contribución por otra es como renovar los cimientos de un edificio sin deshacerlo: operación en la que hay siempre un peligro de ruina (...) Siendo menos sensible al contribuyente el pago de la contribución a que está acostumbrado, precisamente a causa de esa costumbre, en materia de impuestos, conviene conservar todo lo conservable(...) A este fin importa tener presente el sistema de contribuciones que nuestro pueblo argentino acostumbró pagar bajo su antiguo régimen español (...) La reforma del antiguo sistema rentístico fue acometida de un modo irreflexivo y brusco. El entusiasmo tomó el lugar de la reflexión de Estado"3.

En 1975, en oportunidad de la implantación en la Argentina del Impuesto al Valor Agregado (IVA) a nivel nacional, se eliminó la tributación provincial sobre los ingresos brutos. Se sustituyó por una alícuota del IVA superior a la necesaria para reemplazar al impuesto a las Ventas (con esa alícuota diferencial se compensaría la pérdida de ingresos de las provincias) y por la autorización dada a las provincias de establecer Patentes Fijas en base a las características de las actividades gravadas. La experiencia -gran pérdida financiera en medio de una crisis macroeconómica- indicó la necesidad de volver a permitir, a fines de 1975, la aplicación de impuestos sin modificar las alícuotas del IVA.

En 1980 se intentó por parte del gobierno nacional modificar la estructura tributaria provincial, esta vez no eliminando sino transformando el impuesto. La transformación consistía en pasar de una estructura multietápica acumulativa a tasa uniforme, a un impuesto a las ventas en las etapas mayorista y minorista, una alícuota reducida para la industria manufacturera y excepción para la producción agropecuaria. El plan contemplaba la transformación gradual que culminaría en 1985. Nuevamente las pérdidas financieras de las provincias y la crisis macroeconómica hicieron que solo pudieran cumplirse las metas en el primer año (1981) desistiéndose luego de avanzar con el plan.

En 1993 se realiza un nuevo intento, similar al de 1980. Nuevamente las pérdidas financieras y la crisis macroeconómica pusieron fin al plan, que tuvo avances parciales.

3 En su comentario el Prof. Rezk enfatizó la importancia del "acostumbramiento". 
Si bien la eliminación o transformación sustancial del impuesto, prevista tanto 1975,1980 y 1993, fue dejada de lado en cada caso, en la Ley de coparticipación federal de impuestos $23.548 / 88$ se incorporaron varias restricciones respecto del impuesto que forman parte de las Obligaciones asumidas por las provincias para poder participar en el reparto de los recursos fiscales.

I.5. Modelo simple de determinantes políticos de una estructura (composición) tributaria.

En el modelo se supone que el gobierno minimiza el costo político de obtener una recaudación determinada ${ }^{4}$. La estructura tributaria (composición) resulta endógenamente del comportamiento maximizador del agente político. El costo político se mide en términos de votos perdidos, siendo la función

$$
K\left(r_{1}, r_{2}, \ldots . . r_{n} ; X\right)
$$

Donde $r_{i}$ es la participación del impuesto i en la recaudación total y X son las variables que influyen en el costo político.

La función (1) se optimiza sujeta a la restricción $\sum r_{i}=1$, siendo $r_{i}=R_{i} / R$, donde $\mathrm{R}_{\mathrm{i}}$ es la recaudación del impuesto i y $\mathrm{R}$ es la recaudación total a obtener. Para simplificar se supone que los costos políticos de los impuestos son independientes.

Las condiciones marginales de primer orden son,

$$
\frac{\partial K_{i}}{\partial r_{i}}=\lambda \quad \mathrm{i}=1,2, \ldots . \mathrm{n}
$$

El multiplicador de Lagrange es el costo político marginal en términos de votos perdidos. La expresión (2) requiere que la estructura (composición) tributaria sea tal que el costo político marginal de aumentar un peso de recaudación sea igual para todos los tributos.

Resolviendo (2) resulta

$$
r_{i}=r_{i}(X)
$$

4 En un modelo más general la recaudación es endógena y depende del beneficio político del gasto público y del costo político de la recaudación. 
El equilibrio se representa en la Figura 2 para el caso simple de dos impuestos $(1,2)$, uno que grava solo al bien 1 y otro que grava solo al bien 2 . Se supone que los costos políticos marginales son crecientes con la recaudación y son mayores para el caso del impuesto 1. El costo político marginal de la recaudación total es igual a la suma horizontal de los correspondientes a los dos impuestos. Dada una cierta recaudación $R_{0}$ el costo político se minimiza recaudando $R_{l}$ con el impuesto 1 y $R_{2}$ con el impuesto2.

Figura 2. Costo político marginal de la recaudación

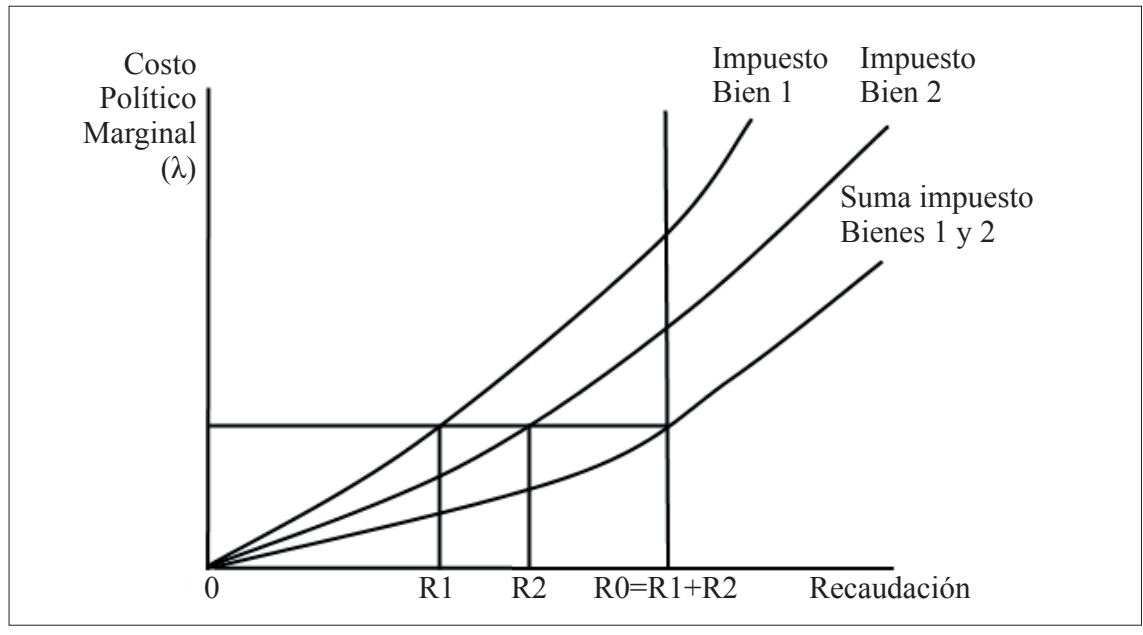

Fuente: Elaboración propia.

La variable más importante en X, en la ecuación (3) es la visibilidad de los impuestos. En los impuestos sobre los inmuebles el costo político es alto dado que se trata de un tributo muy visible -que es lo aconsejable desde el punto de vista de la eficiencia y la rendición de cuentas (accountability). La no coincidencia de los ciclos de los ingresos y de los pagos tributarios de estos impuestos agrega un factor importante de resistencia de los contribuyentes e incrementa su costo político.

El costo político del impuesto a los ingresos brutos es menor ya que no es visible. Cuando incide sobre los consumidores locales va incluido en el precio del bien y se pagan montos pequeños en oportunidad de realizar la compra de los bienes gravados. Existe mayor coincidencia entre los ciclos de los ingresos de la persona y el ciclo de pagos del tributo. La incidencia del impuesto es incierta. Otro factor que puede disminuir el costo político es la posibilidad de exportar el impuesto a 
otras jurisdicciones. En un contexto dinámico, la mayor elasticidad ingreso permite obtener mayor recaudación sin ajuste de los valores fiscales y/o las alícuotas ${ }^{5}$.

\section{ESTRUCTURA DEL IMPUESTO A LOS INGRESOS BRUTOS}

\section{II.1. Evolución entre 1978 y 2010}

A lo largo del tiempo el impuesto experimentó cambios notables en su estructura tal como lo documentan la evolución de las bases imponibles, recaudaciones y alícuotas, a nivel de grandes sectores, entre 1978 y 2010 (Tabla 2). Estos cambios responden a varias causas entre las que se encuentran las diferentes elasticidades-ingreso de las bases imponibles, la influencia de grupos de presión y lobbies, y los cambios en la política tributaria propia o las inducidas por la política nacional. El resultado es un desplazamiento desde los sectores productores de bienes hacia Comercio, Servicios, Intermediación financiera y construcción. La mayoría de los cambios ha ido en la dirección de lo fijado en el Pacto Fiscal para el Empleo, la producción y el crecimiento celebrado entre el gobierno nacional y los estados provinciales en agosto de 1993.

\section{II.2. Modelo teórico de determinantes de la estructura de alícuotas}

En la sección I se utilizó un modelo simple sobre los determinantes de la composición cuando el objetivo es minimizar el costo, en términos de votos perdidos, de obtener una determinada recaudación. Se utilizará ahora un modelo de determinantes políticos de la estructura de alícuotas.

Se supone un impuesto que grava $n$ sectores productivos ${ }^{6}$ con una estructura de alícuotas diseñada de modo de minimizar el costo político de la recaudación. La base imponible está definida de la misma forma para todos los sectores ${ }^{7}$.

5 E. Rezk, en su comentario, sugiere que el "acostumbramiento" es un factor que puede disminuir el costo político.

6 Para simplificar el análisis se consideran distintas alícuotas del mismo impuesto para distintos sectores. El modelo es aplicable a distintos impuestos o bien a distintos contribuyentes del mismo sector y del mismo impuesto.

7 En un modelo más general la minimización del costo político se realiza a través del diseño de toda la estructura legal del impuesto -base imponible, alícuotas, exenciones y deducciones- y de decisiones administrativas que afectan la alícuota efectiva. 
Tabla 2. Evolución de la estructura del impuesto entre 1978 y 2010

\begin{tabular}{lccc}
\hline \multirow{2}{*}{ Categoría } & \multicolumn{3}{c}{ Base imponible } \\
\cline { 2 - 4 } & 1978 & 2010 & Var \% \\
\hline Agricultura, ganadería, caza y silvicultura & 19,4 & 5,4 & $-72,0$ \\
Pesca & 0,3 & 0,1 & $-58,6$ \\
Explotación de minas y canteras & 4,3 & 0,8 & $-82,6$ \\
Industria manufacturera & 44,8 & 31,4 & $-29,9$ \\
Construcción & 2,0 & 4,0 & 103,6 \\
Comercio (mayorista y minorista) & 16,6 & 30,7 & 84,5 \\
Servicios (*) & 11,0 & 18,3 & 65,7 \\
Intermediación financiera & 1,6 & 9,3 & 491,9 \\
\hline Promedio & 100 & 100 & \\
\hline
\end{tabular}

(*) Incluye servicios varios no financieros, tales como hotelería, restaurantes, transporte, comunicaciones, inmobiliarios, alquileres, entre otros.

Fuente: elaboración propia en base a Núñez Miñana y Porto (1981) e información del Ministerio de Economía de la Provincia de Buenos Aires. 
Tabla 2 (continuación). Evolución de la estructura del impuesto entre 1978 y 2010

\begin{tabular}{lccc}
\hline \multirow{2}{*}{ Categoría } & \multicolumn{3}{c}{ Alícuotas implícitas } \\
\cline { 2 - 4 } & 1978 & 2010 & Var \% \\
\hline Agricultura, ganadería, caza y silvicultura & 1,6 & 1,1 & $-33,8$ \\
Pesca & 2,2 & 0,2 & $-89,3$ \\
Explotación de minas y canteras & 2,2 & 1,0 & $-52,3$ \\
Industria manufacturera & 2,2 & 1,2 & $-44,2$ \\
Construcción & 2,2 & 3,4 & 56,6 \\
Comercio (mayorista y minorista) & 2,2 & 3,6 & 62,4 \\
Servicios (*) & 2,4 & 2,7 & 13,3 \\
Intermediación financiera & 4,0 & 5,8 & 45,6 \\
\hline Promedio & 2,1 & 2,7 & 27 \\
\hline
\end{tabular}

Tabla 2 (continuación). Evolución de la estructura del impuesto entre 1978 y 2010

\begin{tabular}{lccc}
\hline & \multicolumn{3}{c}{ Recaudación } \\
\cline { 2 - 4 } Categoría & 1978 & 2010 & Var \% \\
\hline Agricultura, ganadería, caza y silvicultura & 14,5 & 2,1 & $-85,5$ \\
Pesca & 0,3 & 0,0 & $-96,5$ \\
Explotación de minas y canteras & 4,5 & 0,3 & $-93,5$ \\
Industria manufacturera & 46,2 & 14,2 & $-69,3$ \\
Construcción & 2,0 & 5,1 & 150,4 \\
Comercio (mayorista y minorista) & 17,0 & 40,0 & 135,2 \\
Servicios (*) & 12,5 & 18,4 & 47,4 \\
Intermediación financiera & 2,9 & 19,8 & 576,9 \\
\hline Promedio & 100 & 100 & \\
\hline
\end{tabular}

Fuente: elaboración propia 
El costo político se mide en términos de votos perdidos por las alícuotas aplicables a los distintos sectores. La función de costo político viene dada por

$$
K=K\left(r_{1} \ldots r_{n,}, X\right) i=1 \ldots n
$$

Donde $r_{i}$ es ahora la alícuota sobre el sector i y X son otras variables que influyen en el costo político.

La función se optimiza sujeta a la restricción de obtener un cierto nivel de recaudación (S). Para simplificar se supone que los costos políticos de las alícuotas son independientes entre sectores,

$$
\begin{gathered}
L=K\left(r_{1} \ldots r_{n,}, X\right)-\lambda\left(\sum r_{i} q_{i}-S\right) \\
r_{i}=p_{i}-C_{i}^{\prime}
\end{gathered}
$$

Donde $\mathrm{C}^{\prime}{ }_{\mathrm{i}}$ es el costo marginal que se supone constante; $\mathrm{p}_{\mathrm{i}}$ es el precio al consumidor y $\mathrm{q}_{\mathrm{i}}$ es la cantidad producida por el sector i. Los bienes son independientes.

Las condiciones de primer orden son,

$$
\begin{gathered}
\frac{\partial K_{i}}{\partial r_{i}}-\lambda\left(q_{i}+r_{i} \frac{\partial q_{i}}{\partial p_{i}}\right)=0 \\
\sum r_{i} q_{i}-S
\end{gathered}
$$

El multiplicador de Lagrange es el costo político marginal en términos de votos perdidos por peso recaudado,

$$
\lambda=\frac{\partial K}{\partial S}
$$


De (3) resulta,

$$
t_{i}=\frac{r_{i}}{p_{i}}=\frac{\lambda-k_{i}^{\prime}}{\lambda \eta_{i}}
$$
Donde $t_{i}$ es la tasa impositiva en porcentaje del precio final, $k_{i}^{\prime}=\frac{\partial K}{\partial r_{i}} \frac{1}{q_{i}}$
es el costo político marginal por unidad del bien, $\mathrm{y}$

$$
\eta_{i}=-\frac{\partial q_{i}}{\partial P_{i}} \frac{P_{i}}{q_{i}}
$$

es la elasticidad precio de la demanda definida positiva.

La expresión (6) es similar a la regla de Ramsey incluyendo costos políticos. El apartamiento óptimo entre el precio del bien y el costo marginal (alícuota) es mayor cuanto mayor es la recaudación a obtener, menor la elasticidad de la demanda y menor el costo político de recaudar el impuesto.

$$
\begin{gathered}
\frac{\partial t_{i}}{\partial k_{i}^{\prime}}<0(8) ; \frac{\partial t_{i}}{\partial \eta_{i}}<0 \\
\frac{\partial t_{i}}{\partial \lambda}>0
\end{gathered}
$$

Las alícuotas deben ajustarse de modo que en el margen se iguale el costo político por peso recaudado para cada sector. Esto implica una alícuota para cada sector - excepto que sus determinantes lleven al mismo resultado. En la realidad los costos de administración le ponen un límite a la diferenciación de alícuotas ${ }^{8}$.

En la Figura 3 se representa una situación de equilibrio político-económico. Dada la recaudación a obtener $S_{0}$ quedan determinadas, como en la Figura 2, las recaudaciones $R_{l} y R_{2}$. Dadas las curvas de Laffer para cada bien quedan determinadas

8 El límite viene dado por la igualdad entre el costo marginal de administración de una alícuota adicional y el menor costo político marginal por agregar esa alícuota. Siendo $z$ el número al alícuotas en un momento $(z<n)$, la introducción de una alícuota adicional influye tanto del lado del costo político -disminuyéndolo- como de los costos de administración -aumentándolos. 
las alícuotas $r_{1} y r_{2}$. Las relaciones entre $\lambda, R_{i} y r_{i}$ de la Figura es una de las posibles. Las curvas correspondientes a los dos bienes pueden invertir sus posiciones en los dos paneles, dependiendo de los determinantes. Por ejemplo, si en el panel inferior las curvas invierten sus posiciones puede resultar $R_{2}>R_{l}$, pero $r_{2}<r_{1}$ si la demanda por el bien 2 es muy inelástica. En el panel superior la posición de las curvas indican que el costo político de $R_{2}$ es más bajo y más que compensa el efecto elasticidad.

Figura 3. Determinantes políticos y económicos de las alícuotas de un impuesto

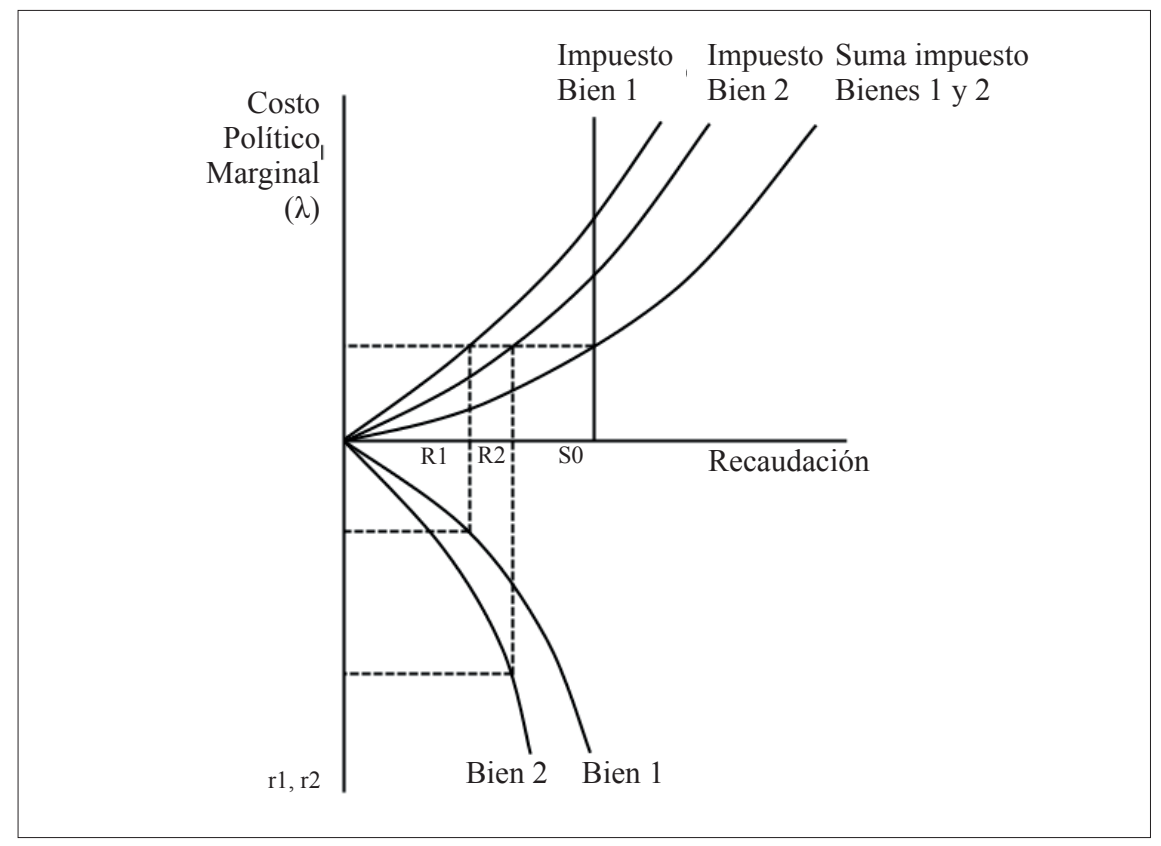

Fuente: Elaboración propia.

II. 3. El caso del impuesto a los Ingresos Brutos en la provincia de Buenos Aires (2010).

La Tabla 3 presenta la información básica del impuesto sobre los ingresos brutos de la Provincia de Buenos Aires para el total de contribuyentes que presentaron las declaraciones juradas: cantidad de contribuyentes, base imponible, impuesto determinado, alícuota implícita y saldo a favor del contribuyente, discriminado por principales actividades (a dos dígitos). 


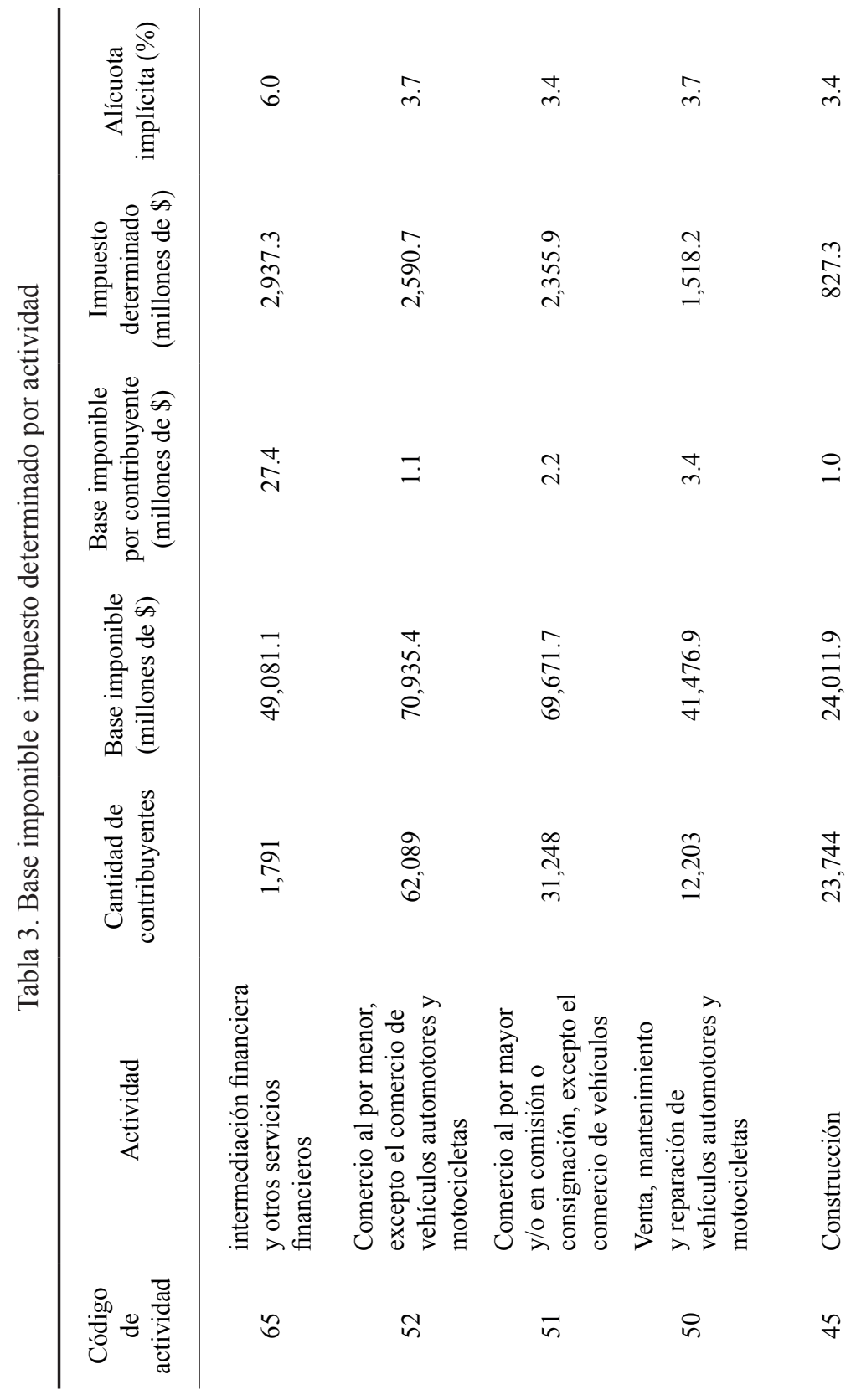


ESTUDIOS ECONOMICOS

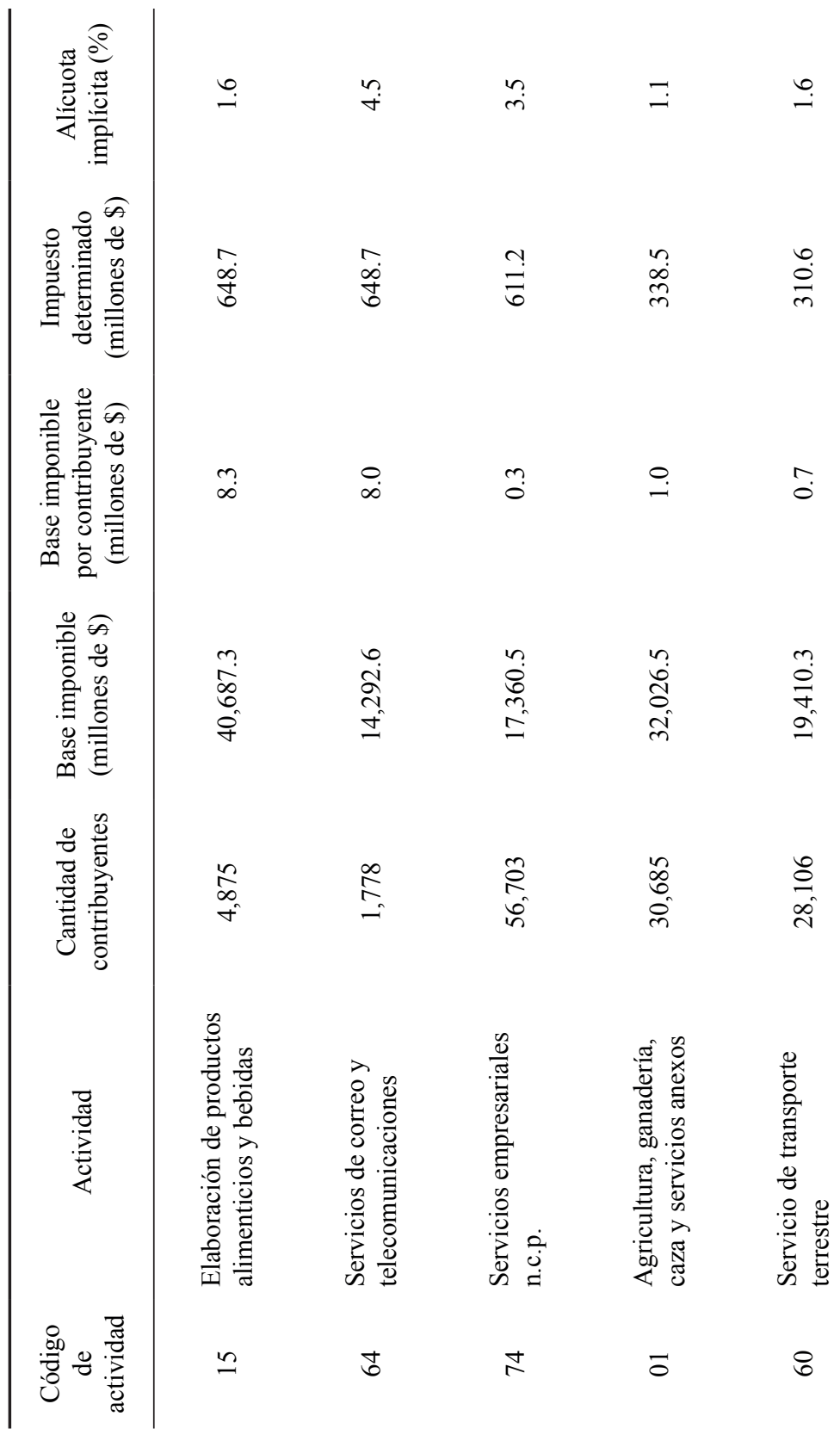




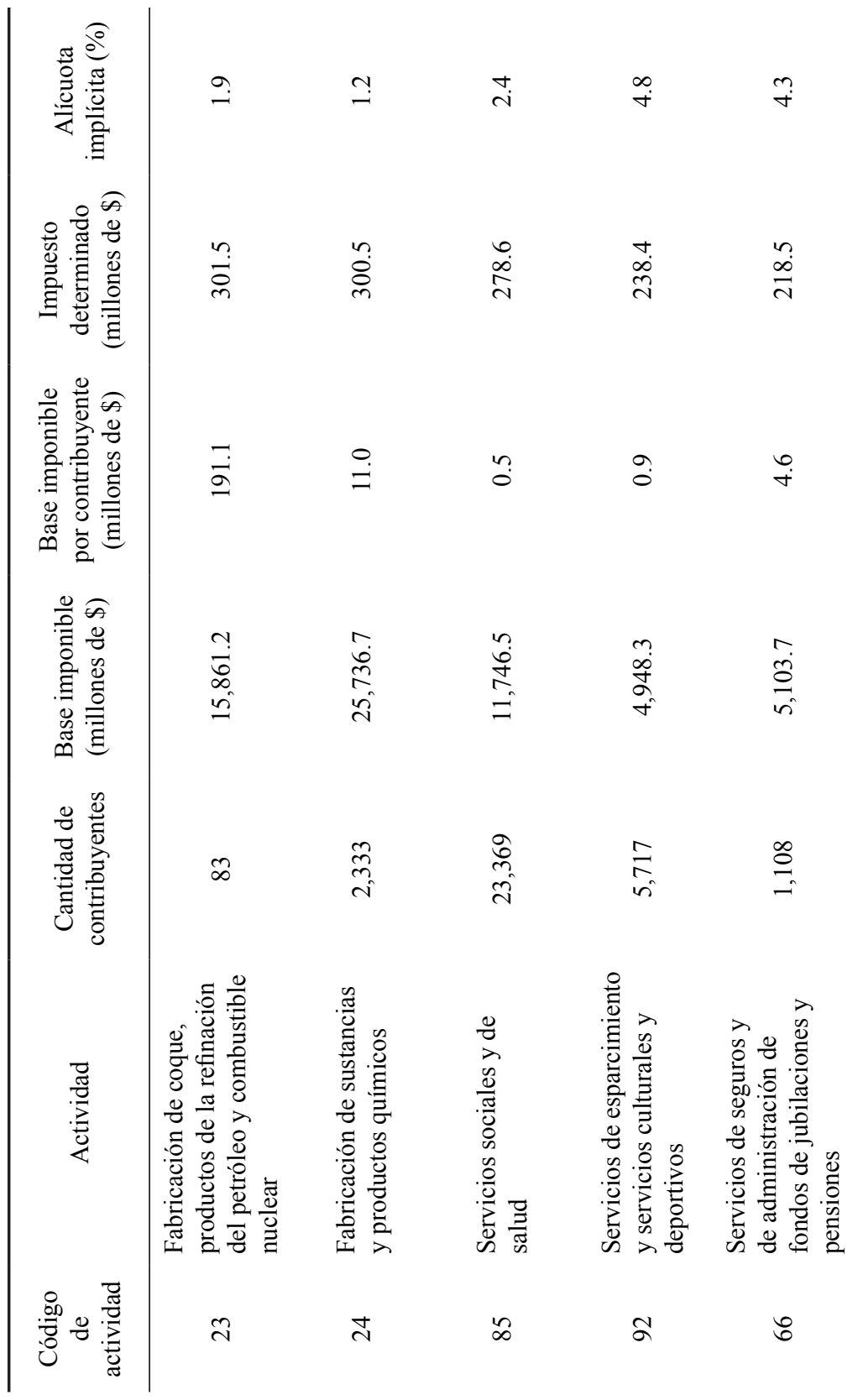


ESTUDIOS ECONOMICOS






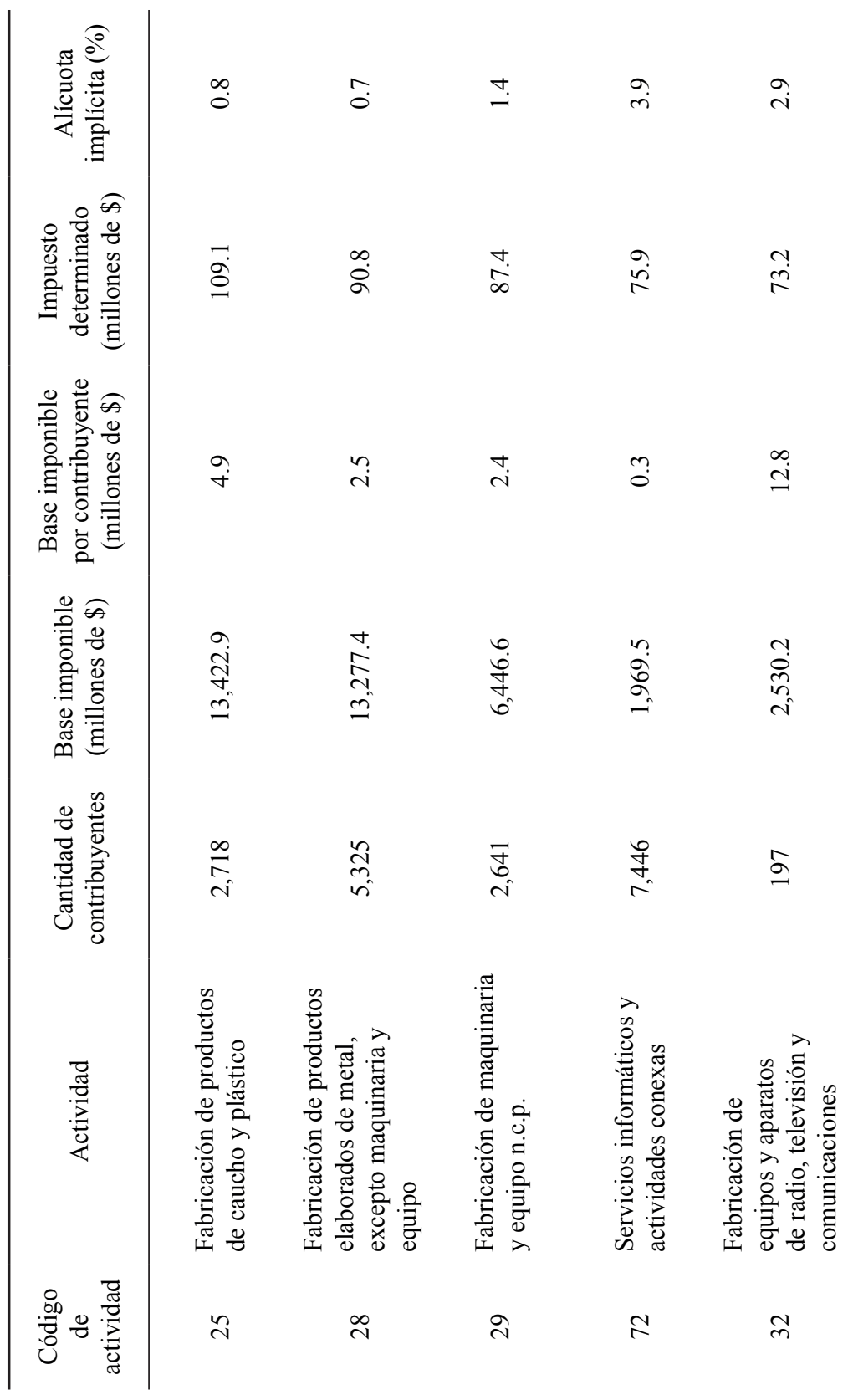


ESTUDIOS ECONOMICOS






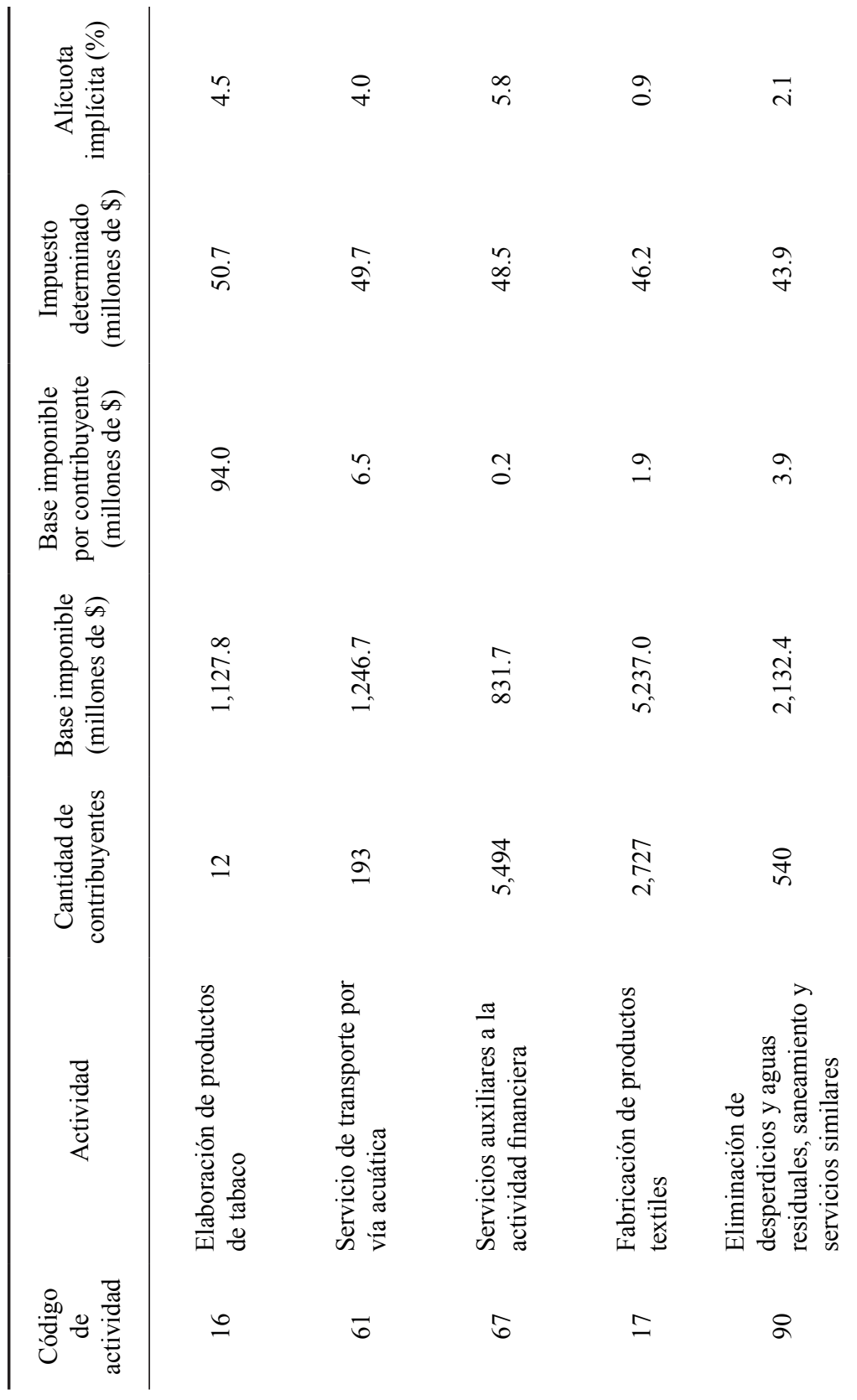


ESTUDIOS ECONOMICOS

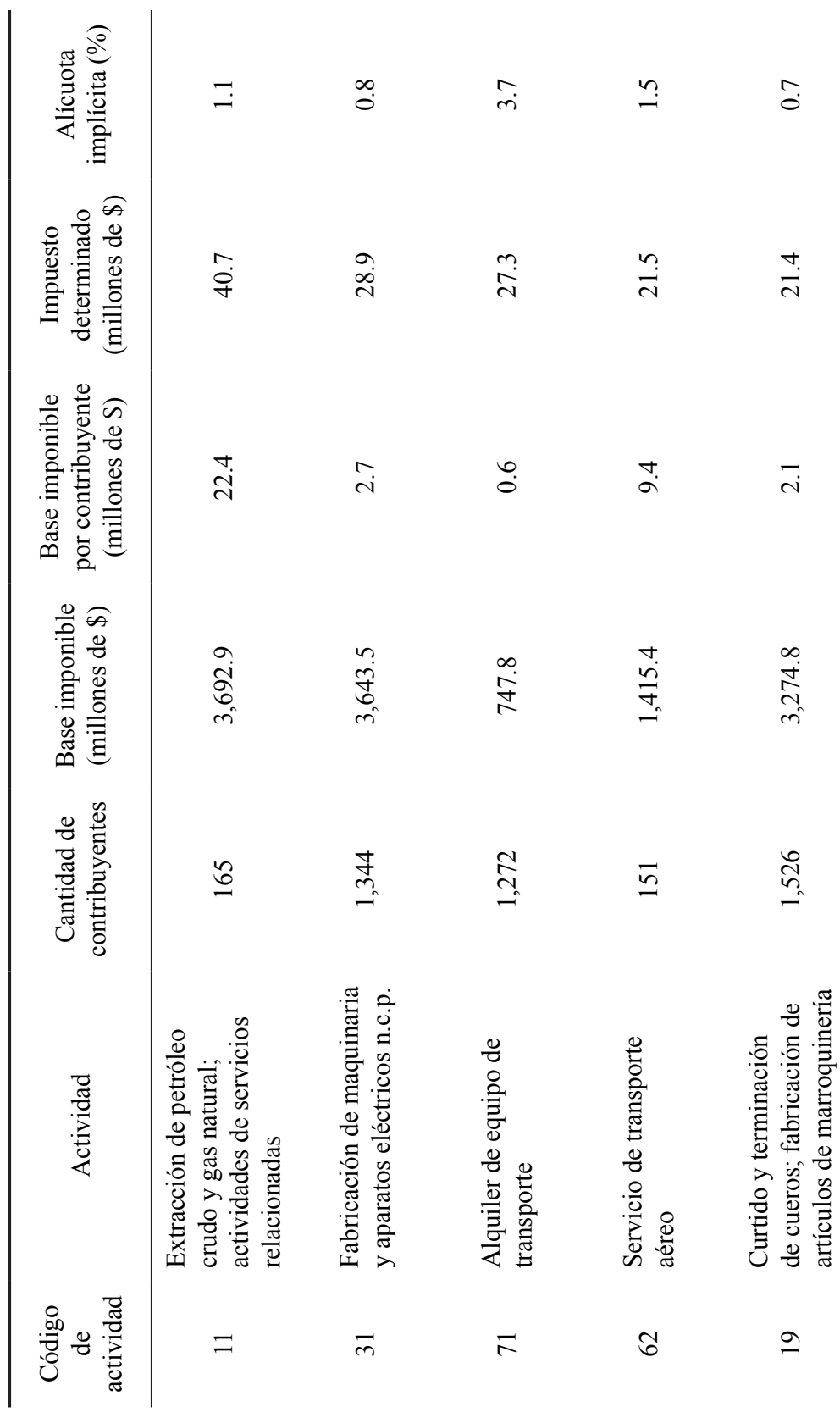




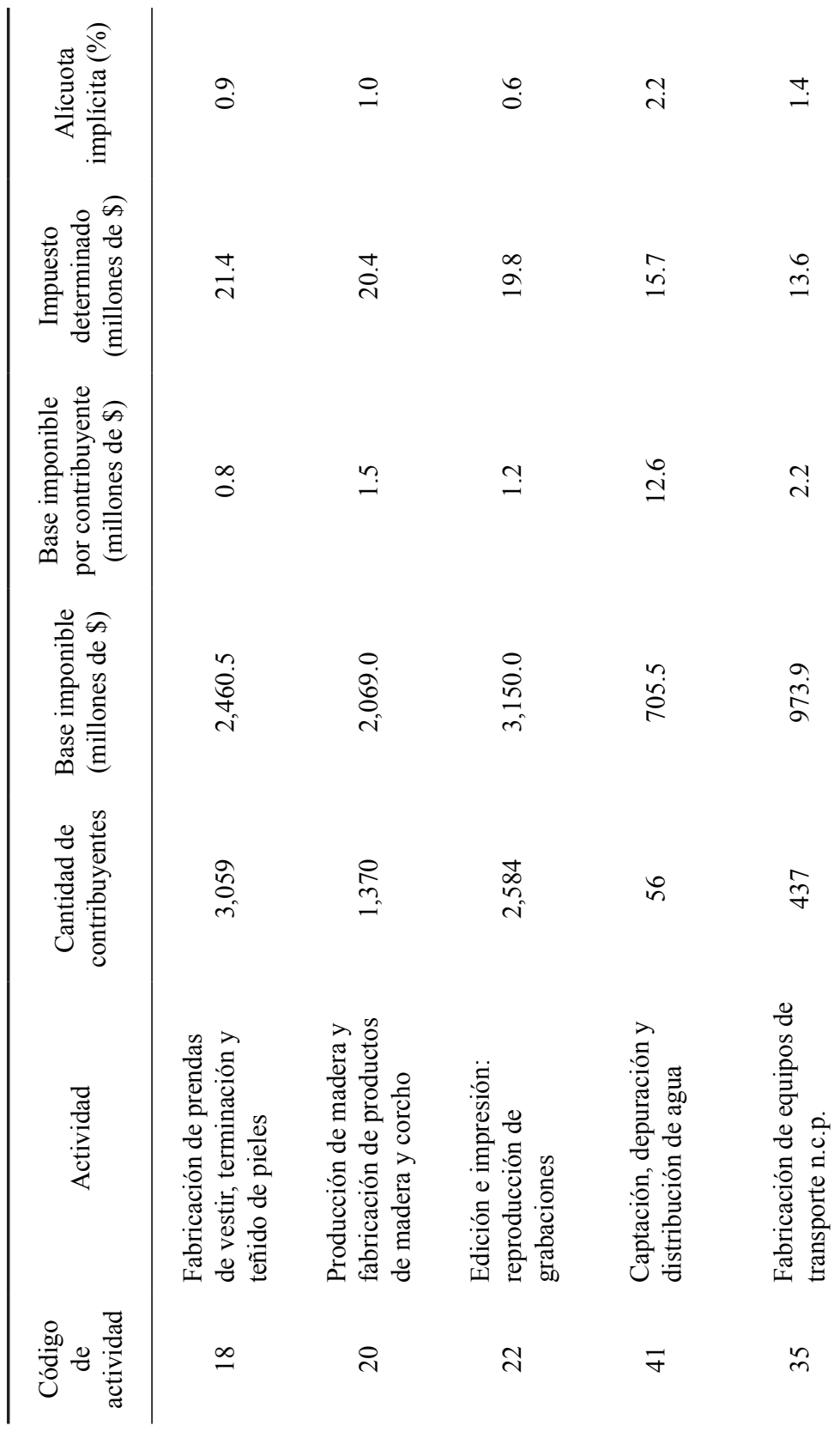


ESTUDIOS ECONOMICOS

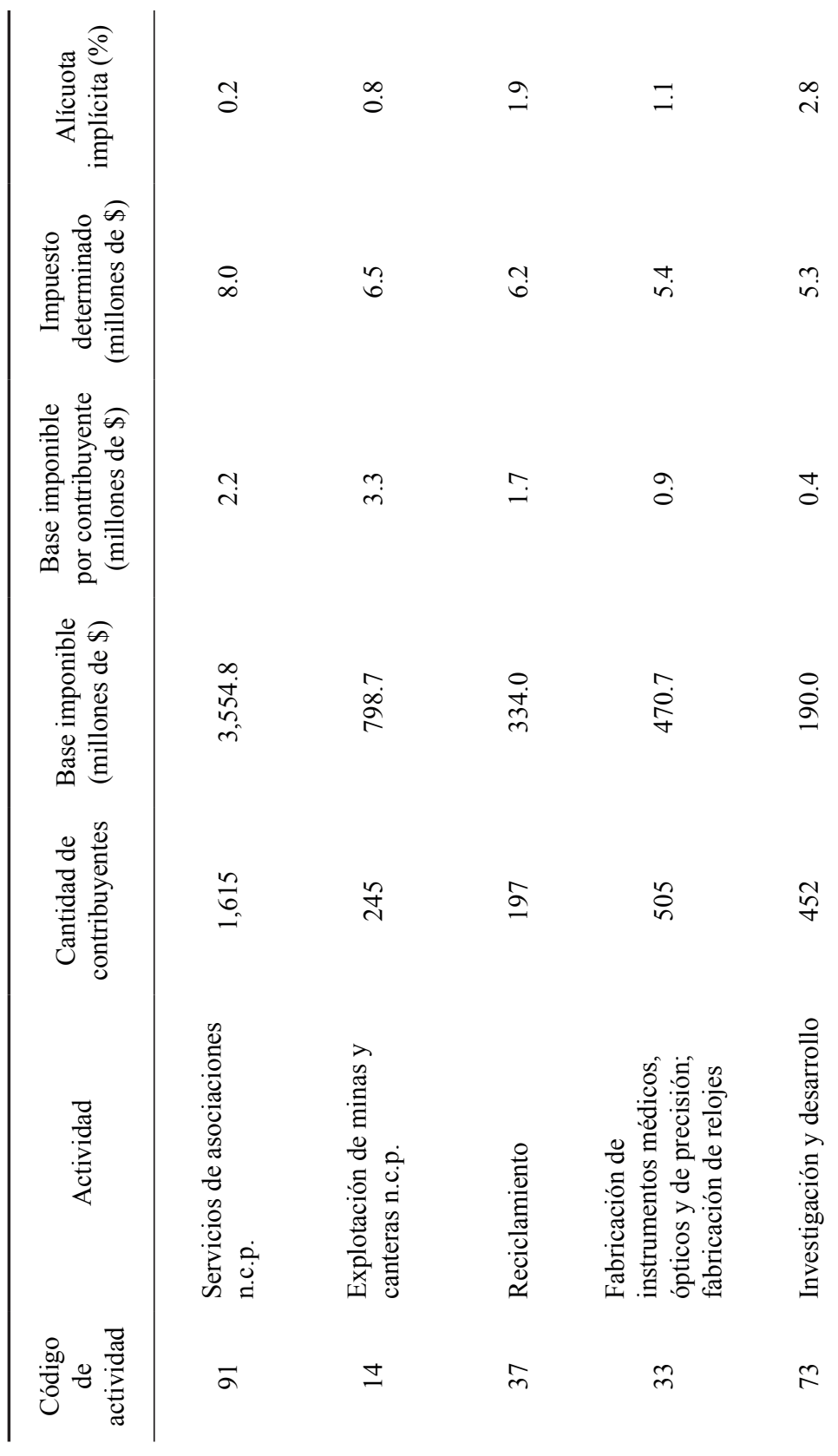




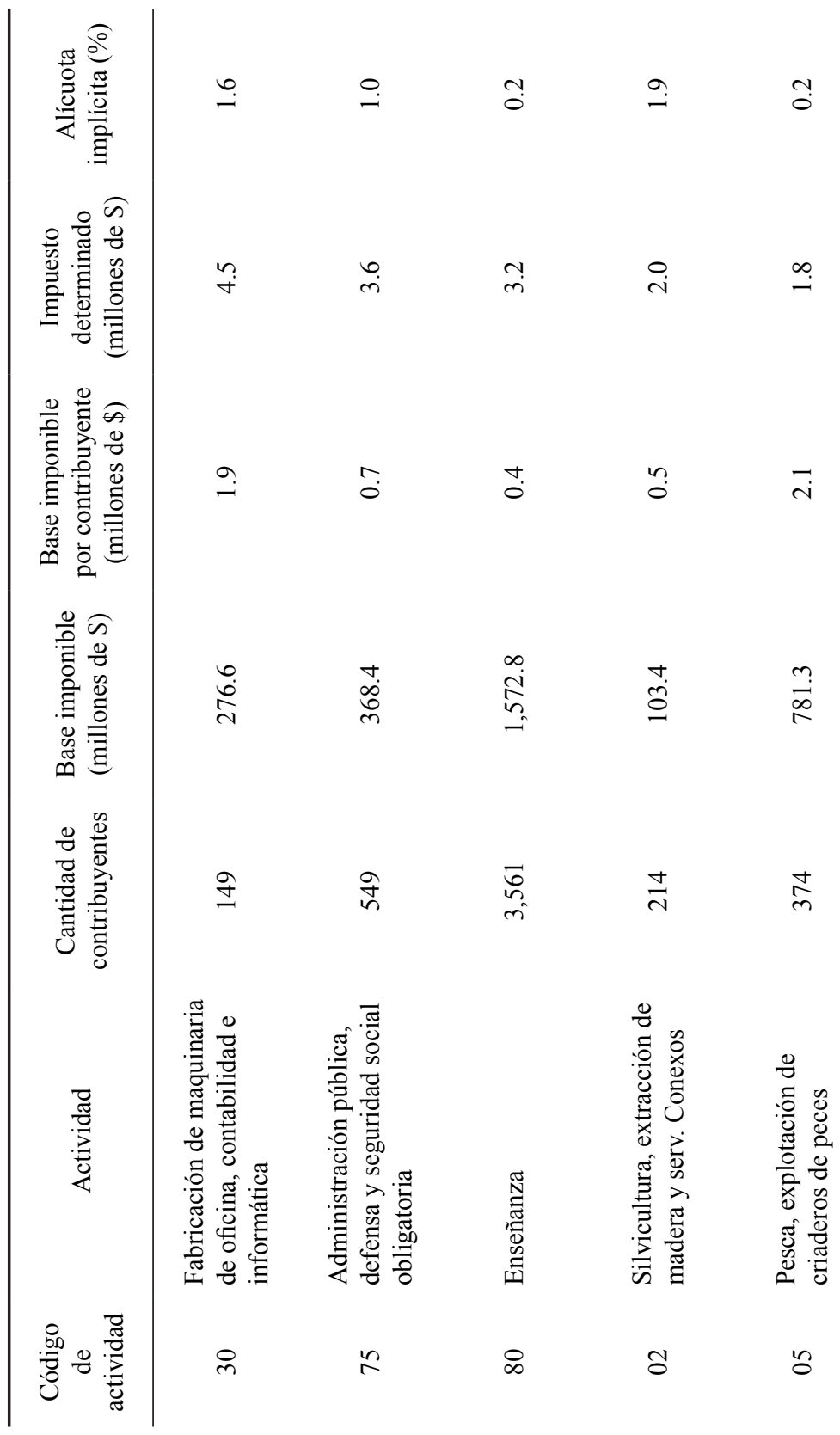


ESTUDIOS ECONOMICOS

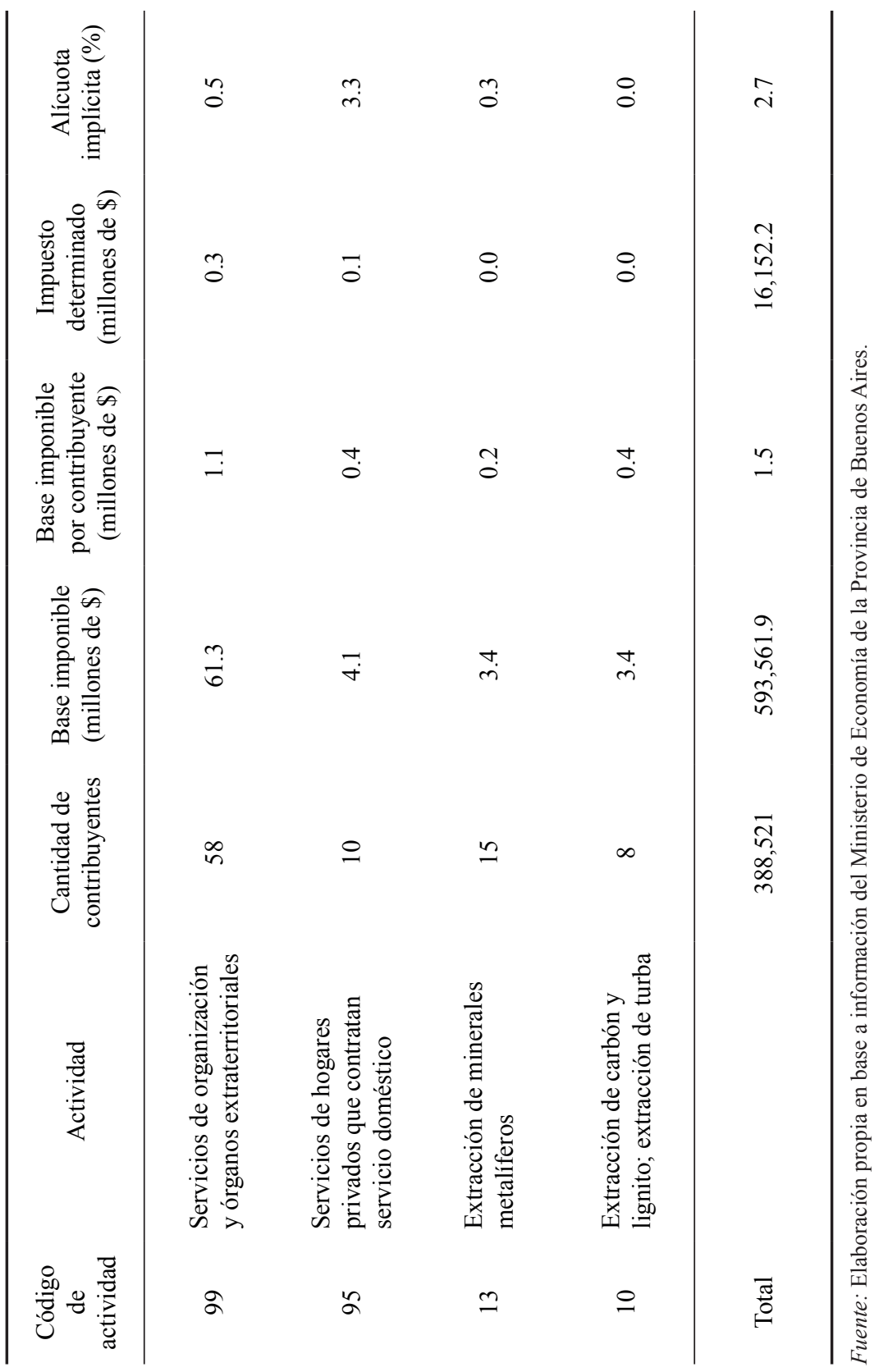


Existen 388.521 contribuyentes agrupados en esta tabla en 57 actividades gravadas (en función de los niveles de actividad a dos dígitos). La base imponible total declarada es $\$ 594.000$ millones. El impuesto determinado total es de $\$ 16.200$ millones. La base imponible promedio por contribuyentes es de $\$ 1,5$ millones. Las ocho principales actividades (servicios de banca minorista, ventas en hipermercados, fraccionadoras de gas licuado, venta de automotores, obras de infraestructura de transporte, elaboración de cervezas y bebidas, telecomunicaciones y transporte de caudales) explican el $75 \%$ del total del impuesto determinado y comprenden el $50 \%$ de los contribuyentes. La alícuota promedio es del $2,7 \%$, pero con una marcada dispersión entre sectores. En general, se observa que la alícuota promedio de las 15 actividades más grandes es del 3\%, superior al promedio general.

En la Tabla 4 se calculan las correlaciones simples entre un conjunto de variables seleccionadas. Es interesante observar que la alícuota promedio de cada actividad está relacionada positivamente con la cantidad de contribuyentes y con la alícuota de la jurisdicción vecina y negativamente con la base imponible por contribuyente. La característica distributiva puede influir en el diseño de la estructura de alícuotas ya que, al considerar aspectos de equidad puede disminuir el costo político de la recaudación. La estimación para cada tipo de bien se obtuvo de Navajas (1999) ${ }^{9}$. El indicador se construye a partir de la información sobre el gasto de los individuos por tipo de bien de la encuesta nacional de gastos e ingresos del año 1996. Para su elaboración se construyó el indicador de desigualdad de Atkinson utilizando un coeficiente de aversión de 0,5. El análisis de correlación no sugiere una asociación estadísticamente significativa de esta variable de características distributivas con las alícuotas correspondientes a estos bienes.

9 La característica distributiva de un bien se define como la suma ponderada de la participación del consumo de cada persona o grupo de personas, siendo el factor de ponderación la utilidad marginal social del ingreso de esa persona o grupo. La utilidad marginal social del ingreso resulta de multiplicar la utilidad marginal privada del ingreso por el valor marginal social de la utilidad. Se sigue a Navajas (1999) a quien se agradece el haber facilitado los cálculos de las características distributivas en base a la Encuesta de Gastos de los Hogares de 1995-96. Puede consultarse también Navajas y Porto (1994). 
Tabla 4. Base imponible e impuesto determinado por actividad

\begin{tabular}{|c|c|c|c|c|}
\hline $\begin{array}{l}\text { Alícuota } \\
\text { promedio } \\
(\text { en } \ln )\end{array}$ & $\begin{array}{c}\text { Base } \\
\text { imponible } \\
\text { por } \\
\text { contrib. } \\
\text { (en ln) }\end{array}$ & $\begin{array}{c}\text { Cantidad } \\
\text { de } \\
\text { contribuyentes } \\
\text { (1) (en ln) }\end{array}$ & $\begin{array}{c}\text { Alícuota } \\
\text { de CABA } \\
(\text { en } \ln )\end{array}$ & $\begin{array}{c}\text { Características } \\
\text { distributivas } \\
\text { (2) }\end{array}$ \\
\hline
\end{tabular}

Alícuota

promedio

1

(en $\ln )$

Base

imponible por contrib.

$-0.2495^{*}$

1

(en $\ln )$

Cantidad de

$\begin{array}{llll}\text { contribuyentes } & 0.3239^{*} & -0.2408^{*} & 1\end{array}$

(1) (en ln)

Alícuota de

CABA (en ln)

0.1939* $-0.0942 *$

$-0,0123$

1

Características

distributivas

(2)

$0,0303 \quad 0.1936^{*} \quad 0.2633^{*} \quad-0.2800^{*} \quad 1$

(*) Nivel de significatividad: $5 \%$

(1) cantidad de contribuyentes por sectores agregados a dos dígitos

(2) Variable de características distributivas de bienes finales con coeficiente de aversión a la desigualdad de 0.5

II.4. Hipótesis sobre los determinantes de los costos políticos de las alícuotas

A partir de los desarrollos anteriores pueden plantearse hipótesis sobre las alícuotas efectivas de los impuestos considerando como determinantes los costos políticos. 
1. Cuanto mayor la cantidad de contribuyentes mayor la alícuota efectiva. El número de contribuyentes en una actividad es importante al momento de organizar grupos para oponerse a alícuotas altas y transferir la carga del impuesto a otros contribuyentes. Conseguir una baja de alícuotas o una alícuota baja es, para el grupo, como un bien público. Una vez obtenida nadie puede ser excluido del beneficio. En grupos grandes la participación de un individuo tiene una influencia mínima y es mayor la posibilidad de comportamientos free-rider. Lo inverso sucede en grupos pequeños que pueden enfrentar los costos fijos de la organización de la oposición ${ }^{10}$. Por esta razón es esperable que, ceteris paribus, la alícuota sea mayor cuanto mayor el número de contribuyentes en la actividad.

2. El costo político es mayor -y la alícuota menor- cuanto mayor la capacidad de lobby del sector, que se supone depende del tamaño de la base imponible por contribuyente.

La base imponible por contribuyente es una medida del beneficio que se obtiene de una baja alícuota o de una disminución de la alícuota. Si la base es muy pequeña también lo es el beneficio y el incentivo a asumir los costos de la oposición. Lo contrario ocurre cuando la base por contribuyente es alta: una pequeña reducción produce beneficios que superan los costos de la oposición. Se espera entonces que las alícuotas varíen, ceteris paribus, en forma inversa con el tamaño de la base imponible.

3. En el diseño de las alícuotas compiten varios objetivos: recaudación, eficiencia, equidad. Si el objetivo de equidad está presente se espera que, ceteris paribus, las alícuotas sean menores para los bienes con mayor característica distributiva.

4. El sistema fiscal de las jurisdicciones vecinas influye al diseñar el de una jurisdicción. Para evitar la competencia tributaria es probable que una provincia prefiera una estructura similar a la de sus vecinos económicos. En ese caso las alícuotas estarán relacionadas positivamente: si una jurisdicción j disminuye sus alícuotas, también lo hará la jurisdicción i. Esa asociación positiva puede ser también consecuencia de la interdependencia de los gastos: si el gasto en i depende positivamente del gasto en $\mathrm{j}$ y el de j del gasto en i, y sus estructuras tributarias son similares, esta asociación positiva se trasladará a las alícuotas de los impuestos.

10 Para la influencia del tamaño del grupo en las decisiones colectivas, ver Olson (1965). 
5. Se espera que las alícuotas por actividades difieran según las características de las mismas (competencia con las mismas actividades de otras provincias, posibilidad de exportar el impuesto, etc.).

El test empírico se realizó para 769 actividades para el año 2010 que es la única información disponible. Se utilizó un modelo de mínimos cuadrados ordinarios, corregido por heterocedasticidad. Se utilizaron las variables exógenas para las que se pudo obtener información. Los resultados se presentan en la Tabla 6.

Tabla 6. Estimaciones econométricas.

Endógena: alícuota implícita promedio por sector (en ln)

Variable

Modelo 1 Modelo 2 Modelo 3 Modelo 4 Modelo 5

Base imponible

por contribuyente

(en $\ln )$

Cantidad de

contribuyentes

$0.141 * * *$

$0.144 * * *$

$0.054 * *$

$0.059 * *$

$0.059 * *$

(en $\ln )(1)$

Alicuota CABA

(en $\ln )$

$0.949 * * * \quad 0.279 * * \quad 0.276 * * \quad 0.302 * * *$

Dummy sector

primario

$-1.129 * * * \quad-1.160 * * *-1.157 * * *$

Dummy sector

industrial

$-0.676 * * * \quad-0.697 * * * \quad-0.700 * * *$

Dummy sector

financiero

$0.728 * * * \quad 0.705 * * * \quad 0.696 * * *$

Dummy comercio

minorista

$\begin{array}{lll}-0.086 & -0.052 & -0.134\end{array}$

Dummy comercio

mayorista

$\begin{array}{lll}0.111 & 0.07 & 0.072\end{array}$


Dummy Bienes finales

o de consumo (2)

$-0.122 *$

Dummy características

distributivas bajas (3)

$-0.212^{* *}$

Dummy características

distributivas altas (4)

0.051

Constante

$-4.031^{* * *} \quad-0.874^{*}$

$-2.260^{* * *}$

$-2.248^{* * *}$

$-2.167 * * *$

$\mathrm{R}^{2}$

0.131

0.171

0.356

0.358

0.360

\section{N}

769

769

769

769

769

$* \mathrm{p}<.1 ; * * \mathrm{p}<.05 ; * * * \mathrm{p}<.01$

Notas:

(1) Agrupados en actividades a dos dígitos.

(2) Dummy donde 1 es todos los sectores de bienes finales cuyo consumo tienen características distributivas y 0 para el resto.

(3) Dummy donde 1 son aquellos bienes de consumos que tienen características distributivas relativamente baja y 0 para el resto.

(3) Dummy donde 1 son aquellos bienes de consumos que tienen características distributivas relativamente alta y 0 para el resto. Para definir estos grupos, se toman el conjunto de bienes de consumos ordenador por el coeficiente de Atkinson en tres grupos (de baja, media y alta características distributivas).

No se pudo descartar que existan variables omitidas (test de Ramsey). Sin embargo, otro test de especificación usual (basado en testear la relación entre la variable endógena y la variable predicha y su cuadrado) sugiere que no existe error de especificación. La endogeneidad es rechazada al introducir como variable la alícuota de la CABA (este punto a sugerencia de Darío Rossignolo). Se controló con el test de Hausman) comparando los coeficientes estimados de los modelos estimados con y sin la variable CABA.

El coeficiente de la base imponible por contribuyente es negativo y significativo en todos los modelos según lo esperado. En el modelo 4 el resultado significa que, al pasar de una actividad a otra, ante un $10 \%$ de incremento en la base por contribuyente la alícuota disminuye en $0,64 \%$. 
El coeficiente de la cantidad de contribuyentes es positivo y significativo en todos los modelos. En el modelo 4, al pasar a una actividad con un 10\% más de contribuyentes, la alícuota aumenta en casi $0,6 \%$.

La relación con la alícuota de las jurisdicciones vecinas es positiva. En el modelo 4 la elasticidad es igual a 0,276. Un 10\% de incremento de las alícuotas de la CABA incrementa las alícuotas de la provincia en $2,76 \%$.

Se utilizó una dummy (igual a la unidad) para las actividades relacionadas con los bienes de consumo final, o sea aquellos en los que pueden diferenciarse las alícuotas si en el diseño se incluyen consideraciones distributivas. El signo es negativo y significativo al $10 \%$ sugiriendo alguna influencia del objetivo de equidad. La variable es un indicador muy imperfecto, razón por la cual se diferenciaron los bienes de consumo final en dos grupos, con características distributivas altas y bajas ${ }^{11}$ (Modelo 5). La dummy correspondiente a bienes con características distributivas bajas es negativa y significativa al 5\% y la de los bienes con características altas es no significativa; estos resultados van en dirección contrario a lo esperado.

La alícuota para las actividades industriales es negativa y significativa. Esto sugiere que se protege a las actividades industriales de la competencia de otras provincias (que puede ser una respuesta a la larga tradición de regímenes de promoción industrial en otras provincias). Es una forma de competencia por inversiones entre jurisdicciones. Puede ser también el resultado de una política nacional para favorecer la competitividad de las actividades industriales frente a la competencia externa. De hecho esta fue la política en el reordenamiento de alícuotas establecida en el Pacto Fiscal II del año 1993. Se intentaba disminuir el "costo argentino" desgravando del impuesto a los ingresos brutos a una serie de actividades, como la industria y la construcción, ya que no favorecía a la exportación.

Las alícuotas del sector financiero son más altas; el coeficiente estimado es positivo y significativo. Puede ser el resultado esperable al tratarse de un impuesto que en gran parte se traslada al contribuyente, la visibilidad es baja y el grupo que carga con el impuesto es grande como para organizar la oposición.

11 Se ordenaron los bienes en dos grupos en base al valor de las características distributivas: altas (por ej. alimentos tales como pan, leche, etc., combustibles tales como kerosene, entre otros bienes) y bajas (como por ej. automotores, turismo y otros servicios). 


\section{CONCLUSIONES}

En este trabajo se estudian aspectos de la estructura del sistema tributario de la Provincia de Buenos Aires. La estructura comprende dos aspectos. Por un lado, la composición de los recursos propios (número e importancia relativa de los impuestos) y, por otro lado, la estructura de los impuestos en particular -en este caso del impuesto sobre los ingresos brutos.

La composición de los recursos propios de la Provincia ha experimentado un cambio notable a lo largo del tiempo. El actual impuesto sobre los Ingresos Brutos ha tenido una participación fuertemente creciente representando en la actualidad tres cuartos de la recaudación total. Ha sustituido como fuente de financiamiento a los otros tributos provinciales, especialmente a los que gravan la propiedad inmueble que pasaron de alrededor del $50 \%$ de lo recaudado hasta mediados del siglo anterior, a menos del $10 \%$ a partir de 2007. A partir de un modelo teórico simple de determinantes políticos de la composición se sugiere que el resultado puede ser explicado en base a la "visibilidad" de los tributos, la posibilidad de exportarlo a otras jurisdicciones, lo incierto de su incidencia, la coincidencia o no entre el ciclo de los ingresos de las personas y el ciclo de los pagos del impuesto, y la elasticidad ingreso de la recaudación. Estos factores políticos, entre otros, explican la importancia creciente del impuesto en la estructura tributaria, pese a las objeciones desde el punto de vista económico que han llevado a Mikesell (2007) a expresar que:

"No sensible case can be made for imposing gross receipts taxes in modern economic environment. The old turnover taxes, typically adopted as desperation measures in fiscal crisis, were replaced with taxes that created fewer economic problems. Gross receipts taxes should never been seen as an element of positive tax reform. They were abandoned for good reasons" ( $p$. 15).

Este conflicto entre recaudación y eficiencia, llevó a la literatura reciente a reconsiderar el rol del impuesto en base, por un lado, a que el desarrollo de las actividades económicas requiere bienes públicos locales y debería pagarse por el beneficio recibido y, por otro lado, a que el impacto sobre la eficiencia debe estudiarse en un contexto de distorsiones pre-existentes (ver, entre otros, Oakland y Testa, 1996; Oates y Schwab, 2004; Mikesell, 2007; Pogue, 2007; Testa y Mattoon, 2007; Bird, 2010).

El costo político puede explicar la estructura de alícuotas. Las estimaciones realizadas en este trabajo sugieren que las alícuotas son mayores en la actividades 
con mayor número de contribuyentes, son menores en las actividades con mayor base imponible por contribuyente, son mayores cuanto mayores las alícuotas de las jurisdicciones vecinas. La influencia de las características distributivas de los bienes en la estructura de alícuotas no es la esperable teóricamente. A nivel de sectores las alícuotas son menores en las actividades industriales (adjudicable a la protección dentro de la provincia) y mayores en actividades financieras (por la mayor posibilidad de traslación, escasa visibilidad y gran número de contribuyentes).

\section{REFERENCIAS BIBLIOGRAFICAS}

Alberdi, J.B. (1854). Sistema Económico y Rentístico de la Confederación Argentina según su Constitución de 1853. Buenos Aires: Ed. Vaccaro.

Arias, R. (2008). Elusión Fiscal en el Impuesto a los Ingresos Brutos. Anales de la Asociación Argentina de Economía Política. XLIII Reunión Anual de la AAEP.

Arias, R. (2010). Ensayos Sobre la Teoría de la Evasión y Elusión de Impuestos Indirectos. Tesis Doctoral, Facultad de Ciencias Económicas de la Universidad Nacional de La Plata.

Ashworth, J., \& Heyndels, B. (2001). Political fragmentation and the evolution of national tax structures in the OECD, International Tax and Public Finance, 8, 377-93.

Bird, R. (2010). Subnational Taxation in Developing Countries. A review of the literature. The World Bank, Policy Research Working Paper 5450.

Chamberlain, A., \& Fleenor P. (2006). Tax Pyramiding: The Economic Consequences of Gross Receipts Taxes, Tax Foundation, Special report Nro. 147, recuperado de http://www.taxfoundation.org/files/sr147.pdf

Cortés Conde, R. \& Harriague, M.M. (2010) Evolución del Sistema Tributario Argentino, IR06 Revista del Instituto AFIP. Recuperado de http://www. afip.gob.ar/instituto/2011/IR06.pdf

Hettich W., \& Winer, S.L. (1984). A positive model of tax structure, Journal of Public Economics, 24, 67-87.

Hettich W., \& Winer, S.L. (1999). Democratic Choice and Taxation: A theoretical and Empirical Analysis. Estados Unidos: Cambridge University Press.

Mikesell J.L. (2007). Gross receipts taxes in State government finances: A review of their history and performance, Tax Foundation, Background Paper, 53.

Musgrave R. (1969). Fiscal Systems. New Haven and London: Yale University Press.

Navajas, F., \& Porto, A. (1994). Budget shares, distributional characteristics and the direction of tax reform, Economic Letters, 45, 475-479. 
Navajas F. (1999). El Impacto Distributivo de los Cambios en Precios Relativos en la Argentina entre 1988-1998 y los Efectos de las Privatizaciones y la Desregulación Económica. Buenos Aires: Fundación de Investigaciones Económicas Latinoamericanas (FIEL).

Núñez Miñana, H. \& Porto, A. (1981). Política Tributaria Provincial: El caso del Impuesto a los Ingresos Brutos. Serie Cuadernos $N^{o} 33$. La Plata: Instituto de Investigaciones Económicas de la Facultad de Ciencias Económicas de la Universidad Nacional de La Plata.

Oakland W.H., \& Testa, W.A. (1996). State-local business taxation and the benefit principle, Economic Perspectives, 2-19.

Oates, W.E., \& Schwab, R.M. (2004). What should local government tax: income or property? En Schwartz A.E. (Ed.), City Taxes, City Spending, (p. 7-29). Cheltenham: Edward Elgar.

Pogue, T.F. (2007). The gross receipts tax: a new approach to business taxation? National Tax Journal, LX(4), 799-819.

Pommerehe, W., \& Schneider, R. (1983). Does government in a representative democracy follow a majority voters' preferences?: an empirical examination, En H. Hanusch (Eds.) Anatomy of government deficiencies (p. 61-84). Londres: Springer.

Puviani, A. (1897). Teoría della illusion en elle entrate publiche, Perugia., vol. VII, Annali dell'Università di Perugia.

Testa W.A. \& Mattoon, R.H. (2007). Is there a role for gross receipts taxation? National Tax Journal, (LX) 4, 799-819.

(C) 2014 por los autores; licencia otorgada a la Revista Estudios Económicos. Este artículo es de acceso abierto y distribuido bajo los términos y condiciones de la licencia Atribución-No Comercial 3.0 Unported (CC BY-NC 3.0) de Creative Commons. Para ver una copia de esta licencia visite http:// creativecommons.org/licenses/by-nc/3.0/ 